\title{
Marine Invertebrate Natural Products for Anti-Inflammatory and Chronic Diseases
}

\author{
Kalimuthu Senthilkumar ${ }^{1}$ and Se-Kwon Kim ${ }^{1,2}$ \\ ${ }^{1}$ Marine Biochemistry Laboratory, Department of Chemistry and Marine Bioprocess Research Center, Pukyong National University, \\ Busan 608-737, Republic of Korea \\ ${ }^{2}$ Department of Chemistry, Pukyong National University, Daeyeon Campus, 599-1, Nam gu, Busan, 608-737, Republic of Korea
}

Correspondence should be addressed to Se-Kwon Kim; sknkim@pknu.ac.kr

Received 11 September 2013; Accepted 10 December 2013

Academic Editor: Edwin L. Cooper

Copyright (c) 2013 K. Senthilkumar and S.-K. Kim. This is an open access article distributed under the Creative Commons Attribution License, which permits unrestricted use, distribution, and reproduction in any medium, provided the original work is properly cited.

\begin{abstract}
The marine environment represents a relatively available source of functional ingredients that can be applied to various aspects of food processing, storage, and fortification. Moreover, numerous marine invertebrates based compounds have biological activities and also interfere with the pathogenesis of diseases. Isolated compounds from marine invertebrates have been shown to pharmacological activities and are helpful for the invention and discovery of bioactive compounds, primarily for deadly diseases like cancer, acquired immunodeficiency syndrome (AIDS), osteoporosis, and so forth. Extensive research within the last decade has revealed that most chronic illnesses such as cancer, neurological diseases, diabetes, and autoimmune diseases exhibit dysregulation of multiple cell signaling pathways that have been linked to inflammation. On the basis of their bioactive properties, this review focuses on the potential use of marine invertebrate derived compounds on anti-inflammatory and some chronic diseases such as cardiovascular disease, osteoporosis, diabetes, HIV, and cancer.
\end{abstract}

\section{Introduction}

Chronic diseases constitute a major cause of mortality and the World Health Organization (WHO) reports chronic noncommunicable conditions to be the leading cause of mortality in the world, representing 35 million deaths in 2005 and over $60 \%$ of all deaths. Each year, more than 30 million deaths ( $52 \%$ of all deaths) by chronic diseases include cardiovascular disease $(30 \%)$, cancer $(13 \%)$, chronic respiratory disease $(7 \%)$, and diabetes (2\%). The global burden of disease resulting from all noncommunicable conditions, which includes premature death and disability, is $49 \%$; $80 \%$ of these deaths occur in low and middle income countries $[1,2]$. Increasing knowledge regarding the impact of diet on human health along with the state-of-the-art technologies has led to significant nutritional discoveries, product innovations, and mass production on unprecedented scale [3]. In particular, naturally occurring bioactive extracts or single compounds are believed to benefit human health and research resulting in substantial advances in nutritional knowledge. There is also growing awareness that dietary source and form of food may affect overall health. Suitably, the role of food as an agent for improving health has been recognized, initiating the development of new classes of compound from marine environment [4].

The marine world, due to its phenomenal biodiversity, is a rich natural resource of many biologically active compounds such as polyunsaturated fatty acids (PUFAs), sterols, proteins, polysaccharides, antioxidants, and pigments. Many marine organisms live in complex habitats exposed to extreme conditions and, in adapting to new environmental surroundings, they produce a wide variety of secondary (biologically active) metabolites which cannot be found in other organisms. Moreover, considering its great taxonomic diversity, investigation related to the search of new bioactive compounds from the marine environment has seen in almost unlimited field $[5,6]$. Marine-based bioactive food ingredients can be derived from many sources, including marine plants, microorganisms, and sponges, all of which contain their own unique set of biomolecules [5]. However, these naturally 


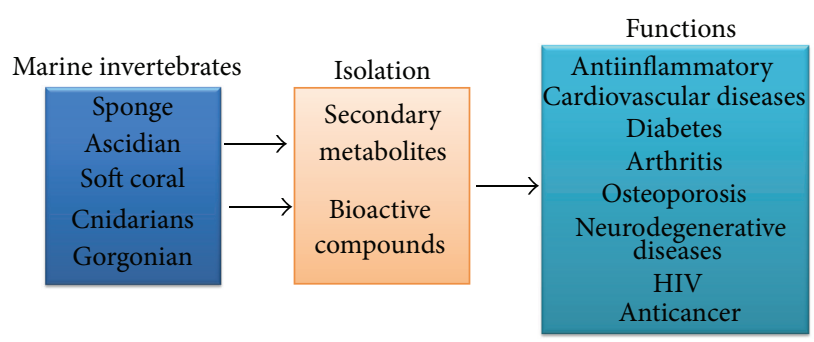

FIGURE 1: Summary of marine invertebrate natural products with anti-inflammatory and some chronic diseases.

occurring bioactive substances has defined health benefit on the human body significantly [3]. Therefore, this review discusses the existing scientific knowledge which demonstrates the suitability of marine derived bioactive compounds for the prevention and treatment of anti-inflammatory and chronic diseases.

\section{Marine Environment and Availability of Natural Products}

Marine biotechnology is the science in which marine organisms are used in full or partially to make or modify products for specific uses. The different molecular and biotechnological methods elucidated for isolating natural products from aquatic and terrestrial organisms. A remarkable number of new natural products (NPs) have been isolated from various marine sources in the past decades [7]. In recent years, many bioactive compounds have been extracted from marine invertebrates such as sponges, tunicates, bryozoans, and mollusca, $[8,9]$. The marine environment covers a wide thermal range including pressure range (1-1000 atm) and nutrient range (oligotrophic to eutrophic) and has extensive photic and nonphotic zones [10]. But with the development of new diving techniques, remote operated machines, and so forth, it is possible to collect marine organisms and during the past decade, over 5000 novel compounds have been isolated from shallow waters to $900-\mathrm{m}$ depths of the sea [11]. The knowledge of the physiological and biochemical features of marine organisms might contribute to the identification of natural products of biomedical importance. Natural products have been the source of most of the active ingredients of medicines. This is widely accepted to be true when applied to drug discovery in "olden times" before the advent of highthroughput screening and the postgenomic era: more than $80 \%$ of drug substances were natural products or inspired by a natural compound [12]. However, comparisons of the information presented on sources of new drugs from 1981 to 2007 and 2010 [13-15] indicate that almost half of the drugs approved since 1994 are based on natural products including marine invertebrates. Marine invertebrates synthesize primary and secondary metabolites that are ultimately screened and described by researchers as NPs. Primary metabolites include amino acids, simple sugars, nucleic acids, and lipids. Secondary metabolites, such as alkaloids, terpenoids, and other compounds, have known bioactivities and biological functions [16]. Thus, marine invertebrate derived compounds may be useful as an alternative medicine for various diseases. Figure 1 provides an overview of this review.

\section{Anti-inflammatory Activity}

Inflammation is part of the complex biological response of vascular tissues to harmful stimuli, such as pathogens, damaged cells, or irritants. The signs of acute inflammation are pain, heat, redness, swelling, and loss of function. Inflammations has different names in different parts of the body asthma (inflammation of the airways), arthritis (inflammation of the joints), dermatitis (inflammation of the skin), and so on. Inflammation is the crucial first step in fighting infection and healing wounds. However, persistent inflammation on immune system is always activated, the condition known as chronic inflammation which leads to chronic diseases [17]. However, if the response is exaggerated, misdirected, or long term, the inflammation can adversely affect health and give rise to many conditions such as inflammatory bowel disease, arthritis, and asthma [18, 19]. Anti-inflammatory refers to the property of a substance or treatment that reduces inflammation. Many steroids and nonsteroidal anti-inflammatory drugs (NSAIDs) are widely used for the treatment for inflammation. Alternately herbal medicines also play a role in inflammation apart from that marine derived bioactive compounds showed antiinflammatory actions. Marine invertebrates are one of the major groups of biological organisms (Porifera, Cnidaria, Mollusca, Arthropoda, Echinodermata, and so forth) that gave until now significant number of natural products and secondary metabolites with pharmacological properties and lead in the formulation of novel drugs. These natural products have a wide range of therapeutic properties, including antimicrobial, antioxidant, antihypertensive, anticoagulant, anticancer, anti-inflammatory, wound healing and immune modulator, and other medicinal effects [20].

Alkaloid is a group of biological amine and cyclic compounds having nitrogen in the ring, naturally occurring in plant, microbes, animals, and marine organisms. Both halogenated and nonhalogenated forms have attracted researchers' interest because of their pharmaceutical importance as bioactive compounds and as biological probes for physiological studies [21]. Indole alkaloids from marine 
TABLE 1

\begin{tabular}{|c|c|c|c|c|}
\hline Name of the compound & Chemistry & Name (species) & Target effects & References \\
\hline Ascidiathiazone & Alkaloids & Ascidian (Ascidian Aplidium) & $\begin{array}{l}\text { Anti-inflammatory action in human } \\
\text { neutrophils }\end{array}$ & {$[27]$} \\
\hline Cembranolides & Cembranoids & Soft coral (Lobophytum crassum) & Inhibitors of COX-2 & [29] \\
\hline Durumolides & Cembranoids & Soft coral (Lobophytum duru) & Inhibitors of iNOS and COX-2 & {$[30]$} \\
\hline Frajunolides & Diterpenoids & Gorgonian (Junceella fragilis) & $\begin{array}{l}\text { Anti-inflammatory action in human } \\
\text { neutrophils }\end{array}$ & {$[31]$} \\
\hline Manzamine & Alkaloids & Sponge sp. & Inhibitors of thromboxane B2 & {$[25]$} \\
\hline Plakortide P & Polyketide & Sponge (P. angulospiculatus) & Antineuroinflammatory & {$[32]$} \\
\hline Rubrolide O & Halogenated furanone & Ascidian (Synoicum sp.) & $\begin{array}{l}\text { Anti-inflammatory action in human } \\
\text { neutrophils }\end{array}$ & {$[28]$} \\
\hline Carteramine A & Alkaloid & Sponge (Stylissa carteri) & Inhibit neutrophil chemotaxis & {$[26]$} \\
\hline
\end{tabular}

invertebrates have reported to be anti-inflammatory potentials; these include conicamin from tunicate [22], Lepadiformines A and B from ascidian [23] and aplysinopsintype compound from sponge Hyrtios erecta [24], manzamine from sponge [25], carteramine A from sponge [26], and ascidiathiazones A and B $[27,28]$ from ascidan. The tricyclic alkaloids ascidiathiazone is isolated from Ascidian aplidium species that affected superoxide production by human neutrophils in vitro $\left(\mathrm{IC}_{50}=0.44-1.55 \mu \mathrm{M}\right)$, as well as ex vivo and studies suggested that these two compounds might become "potential anti-inflammatory pharmaceutical" leads. Cyclooxygenase (COX) enzyme synthesizes prostaglandins, creating inflammation. The new cembranoids, crassumolides A and C from the soft coral Lobophytum crassum inhibited the expression of iNOS and COX-2 ( $\mathrm{IC}_{50}$ less than $\left.10 \mu \mathrm{M}\right)$ [29]. Also, another cembranolides durumolides A-C from the soft coral Lobophytum duru inhibited both iNOS and COX-2 proteins in LPS-activated RAW 264.7 cells in vitro, suggested that the $\alpha$-methylene- $\alpha$-lactone moiety of these compounds was necessary for the activity [30].

A new briarane-type diterpenoids frajunolides B and C, isolated from the Taiwanese gorgonian Junceella fragilis, significantly inhibited superoxide anion and elastase generation from human neutrophils in vitro (apparent $\mathrm{IC}_{50}$ greater than $10 \mu \mathrm{g} / \mathrm{mL}$ ) [31]. Manzamine A, (-)-8-hydroxymanzamine $\mathrm{A}$, and hexahydro-8-hydroxymanzamine, potently inhibited thromboxane (TXB2) generation $\left(\mathrm{IC}_{50}=0.25\right.$, less than 0.1 , and $1.97 \mu \mathrm{M}$, resp.) in brain microglia [25]. Kossuga et al. [32] demonstrated that the polyketide plakortide P isolated from the Brazilian sponge P. angulospiculatus, potently inhibited thromboxane $\mathrm{B} 2$ release $\left(\mathrm{IC}_{50}=0.93 \mu \mathrm{M}\right)$ from activated rat brain microglia, appears to be a potentially "novel anti-neuroinflammatory agent". A halogenated furanone rubrolide $\mathrm{O}$ isolated from a New Zealand ascidian Synoicum sp., which inhibited superoxide anion production in human neutrophils $\left(\mathrm{IC}_{50}=35 \mu \mathrm{M}\right)$ in vitro with low toxicity [28]. A novel dimeric oroidin (type of alkaloid) derivative carteramine A in the marine sponge Stylissa carteri, showed that inhibited neutrophil chemotaxis $\left(\mathrm{IC}_{50}=5 \mu \mathrm{M}\right)$. Because carteramine A has no structural resemblance to known compounds that inhibit neutrophil chemotaxis, their finding provides a "novel platform to develop a new class of antiinflammatory agents" [26]. Some of the anti-inflammatory compounds from marine invertebrates are listed in Table 1.

\section{Chronic Diseases}

A chronic condition is a human health condition or disease that is persistent or otherwise long lasting in its effects. The term chronic is usually applied when the course of the disease lasts for more than three months. Data from the World Health Organization show that chronic disease is also the major cause of premature death around the world. Common chronic diseases include asthma, arthritis, cancer, diabetes, heart diseases, and AIDS. Although chronic diseases are among the most common and costly health problems, they are also preventable and most can be effectively controlled. Apart from available treatment and intervention of drugs from various sources, marine derived compounds play a major role in the health benefits. Therefore, here we discuss the role of marine invertebrate derived natural products for some of the chronic diseases.

4.1. Cardiovascular Disease. Cardiovascular disease (CVD) is a class of diseases that affect the heart, blood vessels (arteries and veins), and blood circulation and is one of the leading causes of mortality and morbidity worldwide. Examples of CVD include atherosclerosis, CHD, stroke, heart failure, deep vein thrombosis, and peripheral arterial disease. The amount of fat in the diet and the type of fatty acids consumed can influence the likelihood of CVD and its risk factors [18]. High blood pressure (hypertension) is one of the major independent risk factors for CVD [33]. Significant discoveries have resulted primarily from analyzing natural products. Marine organisms such as invertebrates derived natural products have pharmacological properties [34]. Eryloside F from sponge Erylus formosus was found to be a potent thrombin receptor antagonist [35]. Thrombin receptor activation is likely to play a key role not only in arterial thrombosis but also in atherosclerosis [36]. Atherosclerosis starts with 
damage to the endothelium and subsequent deposition of fats, cholesterol platelets, cellular waste products, calcium, and other substances in the artery wall. These may stimulate endothelial cells to produce a vascular cell adhesion molecule that results in further buildup of cells and shrinkage of the arterial diameter [37]. Halichlorine from sponge Halichondria okadai is an inhibitor for the expression of vascular cell adhesion molecule 1 [38] and may thus impede atherogenesis [39].

4.2. Diabetes. Diabetes mellitus is a most serious and chronic disease whose incidence rates are increasing with increasing levels of obesity and also with aging of the general population over the world. Currently, an estimated 150 million people worldwide have diabetes and that this will increase to 300 million by 2025 [40]. Globally, type II diabetes (non-insulin dependent diabetes mellitus) accounts for greater than $90 \%$ of the cases [41, 42]. Research for novel anti-diabetic drugs to complement those in present clinical use has intensified over the years [43]. Callyspongynic acid is a polyacetylenic acid isolated from sponge Callyspongia truncata inhibits $\alpha$ glucosidase [44]. $\alpha$-Glucosidase inhibitors interfere with the hydrolysis of glycogen, keeping the glucose concentration in the blood at a lower level, and can be used to treat patients with diabetes 1 [45]. A polybromodiphenyl ether compound isolated from an Indonesian marine sponge Lamellodysidea herbacea inhibits protein tyrosine phosphatase $1 \mathrm{~B}$, an important target for diabetes treatment [46].

4.3. Arthritis and Osteoporosis. Arthritis describes a condition involving inflammation of the joints and is a disease affecting mostly the aged population. Preventing inflammation with its associated pain and reduced mobility symptoms is a primary requirement in arthritis treatment [47]. The alkaloid hymenialdisine isolated from marine sponge Stylissa massa inhibits proteoglycan degradation in bovine articular cartilage [48]. Osteoporosis is a multifactorial progressive skeletal disorder characterized by reduced bone mass and deterioration of bone microarchitecture, predisposing to increased fracture risk [49]. Osteoporosis is called a "silent disease" because it progresses without symptoms until a fracture occurs. Because of larger skeletons and no period of rapid hormonal change, osteoporosis progresses more slowly in men than women [50]. In the recent days, much attention has been paid for marine compounds for osteoporosis treatment [51]. Norzoanthamine is one of the zoanthamine classes of marine alkaloids isolated from a colonial zoanthid (cnidarians), Zoanthus sp. [52]. Norzoanthamine could protect skeletal proteins, such as collagen and elastin in the host animal bodies from external stresses and possibly enhance survival as it may be a promising drug candidate for osteoporosis treatment and prevention [53].

4.4. Neurodegenerative Diseases. Neurodegeneration is the term for the progressive loss of structure or function of neurons, including death of neurons. Many neurodegenerative diseases including Alzheimer's disease, Parkinson's disease, and Huntington's disease occur as a result of neurodegenerative processes. Current interventions for Alzheimer's disease (AD) include acetylcholinesterase inhibitors (AchI), which are indicated for patients with mild to moderate symptoms. A spectrum of alternative treatments for $\mathrm{AD}$ has also been proposed and must be examined judiciously in preclinical, clinical, and evidence-based research (EBR) studies [54]. Therefore, search for acetylcholinesterase inhibitors is useful for the treatment of Alzheimer's disease. Pharmacological studies with marine compounds affecting the nervous system involved three areas of neuropharmacology: the stimulation of neurogenesis, the targeting of receptors, and other miscellaneous activities on the nervous system. A new stigmastane type steroidal alkaloid 4-acetoxy-plakinamine B isolated from a Thai marine sponge Corticium sp. significantly inhibited acetylcholinesterase $\left(\mathrm{IC}_{50}=3.75 \mu \mathrm{M}\right)$. This compound is reported to be the "first marine derived acetyl cholinesteraseinhibiting steroidal alkaloid" [55]. The inflammatory component to the pathology of neurodegeneration was most notably in Alzheimer's disease but also in Parkinson's disease and motor neuron disease [56]. Hymenialdisine is an alkaloid isolated from marine sponges, such as Acanthella aurantianca and Stylissa massa [57]. Hymenialdisine inhibits phosphorylation of the protein tau (which is hyperphosphorylated in Alzheimer's disease) with promising potential against human neurodegenerative diseases [58]. 11-Dehydrosinulariolide was obtained from formosan soft coral, S. flexibilis, promoting neuroprotective properties as a promising candidate for the treatment of Parkinson's disease [59].

4.5. HIV/AIDS. In order to combat the human immunodeficiency virus (HIV), diverse strategies have been developed to research on compounds which can be developed as therapeutic agents. Complementary and alternative medicine (CAM) can be defined as any treatment used in conjunction (complementary) or in place of (alternative) standard medical treatment [60]. More research is also required on the harmful and beneficial effects of concurrent CAM and treatment for HIV/AIDS. However, for all other types of CAM, natural products may be the alternative medicinal use for HIV/AIDS. Among them, marine derived natural products may be useful for the treatment of HIV. The peptides tachyplesin and polyphemusin, which are highly abundant in hemocyte debris of the horseshoe crabs Tachypleus tridentatus, Limulus polyphemus and the sponge metabolites avarol, avarone, ilimaquinone and several phloroglucinols has anti HIV activity $[61,62]$. Avarol inhibits HIV by completely blocking the synthesis of the natural UAG suppressor glutamine transfer tRNA. Avarol inhibits HIV by almost completely blocking the synthesis of the natural UAG suppressor glutamine transfer tRNA. Synthesis of this tRNA is upregulated after viral infection and important for the synthesis of a viral protease, which is necessary for viral proliferation [63].

Clathsterol, a novel and active sulfated sterol from the Red Sea sponge Clathria sp., has been shown that inhibits HIV-1 RT at $10 \mu \mathrm{M}$ concentration [64]. An HIV-inhibitory cyclic depsipeptide microspinosamide, isolated from the marine 
TABLE 2: List of some marine invertebrate derived natural products for chronic diseases.

\begin{tabular}{|c|c|c|c|c|}
\hline Name of the compound & Chemistry & Name (species) & Target effects & References \\
\hline Eryloside F & $\begin{array}{c}\text { Penasterol } \\
\text { disaccharide }\end{array}$ & Sponge (Erylus formosus) & Atherosclerosis & {$[35]$} \\
\hline Halichlorine & Alkaloid & Sponge (Halichondria okadai) & Atherosclerosis & {$[38]$} \\
\hline Callyspongynic acid & Polyacetylenic acid & Sponge (Callyspongia truncate) & Diabetes & {$[44]$} \\
\hline Hymenialdisine & Alkaloid & Sponge (Stylissa massa) & Arthritis & {$[48]$} \\
\hline Norzoanthamine & Alkaloid & Cnidarians, Zoanthus sp. & Osteoporosis & {$[53]$} \\
\hline 4-Acetoxy-plakinamine B & Alkaloid & Sponge (Corticium sp.) & $\begin{array}{l}\text { Acetylcholinesterase } \\
\text { inhibition }\end{array}$ & {$[55]$} \\
\hline Hymenialdisine & Alkaloid & $\begin{array}{l}\text { Sponge Acanthella aurantiaca } \\
\text { and Stylissa massa }\end{array}$ & Alzheimer's disease & {$[57]$} \\
\hline 11-dehydrosinulariolide & Cembranolide & Soft coral (S. flexibilis) & Parkinson's disease & {$[59]$} \\
\hline Avarol & $\begin{array}{l}\text { Sesquiterpene } \\
\text { hydroquinone }\end{array}$ & Sponge sp. & HIV & {$[63]$} \\
\hline Clathsterol & Depsipeptide & Sponge (Clathria sp.) & HIV & {$[65]$} \\
\hline Crambescidin 826 & Alkaloid & Sponge (Monanchora sp.) & HIV & {$[66]$} \\
\hline Dehydrofurodendin & Furanoterpene & $\begin{array}{l}\text { Sponge } \\
\text { (Madagascan Lendenfeldia) }\end{array}$ & HIV & {$[67]$} \\
\hline Neamphamide A & Depsipeptide & Sponge (Neamphius huxleyi) & HIV & {$[68]$} \\
\hline Lamellarins & Alkaloid & Mollusks (Lamellaria sp.) & HIV & {$[73]$} \\
\hline Tachyplesins & Peptide & $\begin{array}{l}\text { Horseshoe crabs } \\
\text { Tachypleus tridentatus and } \\
\text { Limulus polyphemus }\end{array}$ & HIV & {$[75]$} \\
\hline
\end{tabular}

sponge Sidonops microspinosa, inhibits HIV-1 infection in cell based in vitro assays [65]. A new polycyclic guanidine alkaloid, crambescidin 826, was reported from the marine sponge Monanchora sp. and it inhibits HIV-1 envelopemediated fusion in vitro $\left(\mathrm{IC}_{50}=1-3 \mu \mathrm{M}\right)$; it suggested that this compound might be the design of small molecule HIV1 fusion inhibitors [66]. A new C22 furanoterpene (dehydrofurodendin) was isolated from the Madagascan Lendenfeldia sponge, active against HIV-1 RT-associated RNA- and DNA-directed DNA polymerase $\left(\mathrm{IC}_{50}=3.2-5.6 \mu \mathrm{M}\right)$ [67]. Neamphamide A was isolated from the Papua New Guinea marine sponge Neamphius huxleyi that inhibits the cytopathic effect of HIV-1 infection in cell based in vitro assays $\left(\mathrm{EC}_{50}=\right.$ $28 \mathrm{nM}$ ) [68]. Two bisquinolizidine alkaloids, petrosin and petrosin A was isolated from the Indian marine sponge Petrosia similes inhibits HIV-1 replication, formation of giant cells and recombinant reverse transcriptase in vitro [69]. Didemnaketals A and B were isolated from the ascidian Didemnum sp. and found to be inhibitors of HIV-1 protease [70]. Bioassay-guided fractionation of extracts of the Palauan ascidian Didemnum guttatum led to the isolation of cyclodidemniserinol trisulfate as an inhibitor of HIV-1 integrase [71]. Lamellarins was first isolated from prosobranch mollusks of the genus Lamellaria and subsequently obtained from Didemnid ascidians [72]. Lamellarin inhibits the integrase terminal cleavage activity and strands transfer activity [73]. The peptides Tachyplesins I-III and polyphemusins I and II, which are highly abundant in hemocyte debris of the horseshoe crabs Tachypleus tridentatus and Limulus polyphemus, respectively, were found to be HIV cell fusion inhibitors $[74,75]$. Some of the marine natural products for chronic diseases are listed in Table 2.

4.6. Cancer. Many potent natural products which display effective anticancer activities have been discovered in the marine environment. Indeed, since the early 1990s, there has been a dramatic increase in the number of preclinical anticancer compounds from marine sources that have entered human clinical trials $[14,76]$. Marine derived natural products from marine invertebrates are the valuable sources for anticancer drugs. Trabectidin (Yondelis), originally isolated from the Caribbean marine tunicate Ecteinascidia turbinate, has been approved for use as an anticancer agent in Europe $[77,78]$. The compound was selected for clinical development on the basis of its novel chemical structure and its striking activity against tumor cell lines of different origins in vitro and in vivo models. In 2007, trabectedin obtained marketing authorization from the European Commission for the treatment of patients with advanced soft tissue sarcoma. In 2009, it received marketing authorization from the European Commission in combination with pegylated liposomal doxorubicin for the treatment of patients with relapsed platinum sensitive ovarian cancer. Clinical activity is currently being evaluated in other neoplasms, including prostate and breast 
TABLE 3: List of some anticancer natural products from marine invertebrates.

\begin{tabular}{|c|c|c|c|c|}
\hline $\begin{array}{l}\text { Name of the } \\
\text { compound }\end{array}$ & Chemical class & Source of organisms & Targets & Reference \\
\hline Trabectidin & Alkaloids & $\begin{array}{l}\text { Tunicate (Ecteinascidia } \\
\text { turbinate) }\end{array}$ & $\begin{array}{l}\text { Anticancer effect in breast and prostate and } \\
\text { so forth. }\end{array}$ & {$[77,78]$} \\
\hline Kahalalide F & Cyclic depsipeptide & Mollusk (Elysia rufescens) & Inhibits topoisomerase II in cancer & {$[81]$} \\
\hline Heteronemin & Sesterterpene & Sponge (Hyrtios sp.) & Inhibits Leukemia (K562 cells) cancer cells & {$[82]$} \\
\hline $\begin{array}{l}\text { Tyrindoleninone } \\
\text { and 6-bromoisatin }\end{array}$ & Indole derivative & Mollusk (Dicathais orbita) & $\begin{array}{l}\text { Inhibits ovary, granulosa, choriocarcinoma } \\
\text { (OVCAR-3, KGN, Jar) cells }\end{array}$ & [83] \\
\hline Makaluvamine A & Pyrroloquinoline & Sponge (Zyzzya fuliginosa) & Colon cancer (HCT-116 cells) inhibition & {$[84]$} \\
\hline Ascididemin & Alkaloid & $\begin{array}{l}\text { Mediterranean ascidian } \\
\text { (Cystodytes dellechiajei) }\end{array}$ & $\begin{array}{l}\text { Inhibits leukemia (HL-60 and P388) cancer } \\
\text { cells }\end{array}$ & {$[85,86]$} \\
\hline Lamellarin D & Alkaloid & $\begin{array}{l}\text { Prosobranch mollusc of the } \\
\text { genus (Lamellaria) }\end{array}$ & Inhibits leukemia cancer cells & {$[87,88]$} \\
\hline Spongistatin 1 & Macrocyclic lactone & $\begin{array}{c}\text { Sponges } \\
\text { (Spirastrella spinispirulifera } \\
\text { and Hyrtios erecta) }\end{array}$ & $\begin{array}{l}\text { Inhibits leukemia } \\
\text { (Jurkat) cancer cells }\end{array}$ & {$[89]$} \\
\hline Chitosan & Polysaccharides & $\begin{array}{l}\text { Crabs and shrimp } \\
\text { (various species) }\end{array}$ & $\begin{array}{l}\text { Inhibits and induces apoptosis of HeLa } \\
\text { cancer cell }\end{array}$ & {$[90]$} \\
\hline Bryostatins & Macrolides & Bryozoan (Bugula neritina) & $\begin{array}{l}\text { Inhibits various cancer types and currently } \\
\text { used in clinical trials }\end{array}$ & {$[91]$} \\
\hline $\begin{array}{l}\text { Eribulin mesylate } \\
\text { (E7389) }\end{array}$ & Macrolide & $\begin{array}{l}\text { Halichondria okadai and } \\
\text { Axinella family }\end{array}$ & $\begin{array}{l}\text { Microtubule inhibitor and presently used in } \\
\text { clinical trials }\end{array}$ & {$[93]$} \\
\hline Aplidin & Cyclic depsipeptide & $\begin{array}{c}\text { Ascidian } \\
\text { (Aplidium albicans) }\end{array}$ & $\begin{array}{l}\text { Currently in phase II/III clinical trials for } \\
\text { solid and hematologic malignancies }\end{array}$ & {$[96]$} \\
\hline
\end{tabular}

cancer. Trabectedin's mechanism of action seems to be different from that of the available DNA damaging agents used in cancer chemotherapy to date. The cytoskeleton is also an interesting target for cancer therapy, as the microtubules and microfilaments are involved in cellular organization during cell division. A number of compounds from marine sponges and ascidians are microtubule inhibition [79]. Kahalalide F, a cyclic depsipeptide from the herbivorous marine mollusk, Elysia rufescens, has shown to be effective against cancer cell lines with strong multidrug resistance and against cell lines resistant to topoisomerase II inhibitors. In vivo models have also confirmed anticancer activity in various solid tumor models [80, 81].

The heteronemin, a marine sesterterpene isolated from the sponge Hyrtios sp., inhibits NF- $\kappa \mathrm{B}$ activation and activates both initiator caspase- 8 and caspase-9, which are implicated in the extrinsic and intrinsic apoptotic pathway, respectively, in chronic myelogenous leukemia cells [82]. Tyrindoleninone and 6-bromoisatin are indole derivatives from marine mollusk Dicathais orbita that induces apoptosis in female reproductive cancer cell lines ovary, granulosa, and choriocarcinoma (OVCAR-3, KGN, Jar), respectively [83]. Makaluvamine A is a pyrroloquinoline, principally isolated from the sponge Zyzzya fuliginosa that has potent anticancer activity in HCT-116 cells [84]. Ascididemin (ASC), a aromatic alkaloid isolated from the Mediterranean ascidian Cystodytes dellechiajei [85], which are strong inducer of apoptosis in HL-60 and P388 leukemia cells [86]. An alkaloid Lamellarin D (LAM-D), initially isolated from a prosobranch mollusc of the genus Lamellaria, exhibits cytotoxicity against many different tumors. LAM-D potently stabilizes topoisomerase I DNA covalent complexes to be promoting the formation of DNA single strand breaks. LAM-D also promotes nuclear apoptosis in leukemia cells via the intrinsic apoptotic pathway $[87,88]$. Spongistatin 1 a macrocyclic lactone isolated from the marine sponges Spirastrella spinispirulifera and Hyrtios erecta induces apoptosis by interact with caspase dependent pathway by the release of cytochrome c, Smac/DIABLO, and Omi/HtrA2 from the mitochondria to the cytosol, leading to apoptosis in Jurkat cells [89]. Chitosan is produced commercially by deacetylation of chitin, which has the structural element in the exoskeleton of crustaceans (such as crabs and shrimp) and cell walls of fungi. Diethylaminoethyl chitosan induces apoptosis in HeLa cells via activation of caspase- 3 and p53 expression [90]. Bryostatins are a group of macrolide lactones first isolated in the 1960s by George Pettit from extracts of a species of bryozoan, Bugula neritina. The structure of bryostatin 1 was determined in 1982. To date 20 different bryostatins has been isolated, those are currently under investigation as anti-cancer agents $[91,92]$. Bryostatin 1 induces apoptosis in HL-60 chronic lymphocytic leukaemia and also acts synergistically in combination with other anticancer drugs.

Eribulin mesylate (E7389) is a microtubule dynamics inhibitor that is a simplified, synthetic analog of the marine natural macrolide halichondrin $\mathrm{B}$, which was first isolated from the Japanese sponge Halichondria okadai [93] and subsequently from several unrelated sponges belonging to the Axinella family. Eribulin mesylate is now in phase I clinical studies exploring weekly and 3-week schedule [94]. Aplidine 
is a cyclic depsipeptide extracted from the ascidian Aplidium albicans [95]. It is a member of the class of compounds known as didemnins. Aplidin is a novel cyclic depsipeptide, currently in phase II/III clinical trials for solid and hematologic malignancies [96]. Hemiasterlin is originally identified as natural products from marine sponges (Cymbastela sp., Hemiasterella minor, Siphonochalina sp., and Auletta sp.), comprising a small family of naturally occurring tripeptides containing three highly modified amino acids $[97,98]$. Hemiasterlin is a potent inhibitor of cell growth, depolymerizes microtubules, and arrests cells in the G2-M phase of the cell cycle [99]. Elisidepsin (PM02734, Irvalec) is a synthetic marine derived cyclic peptide of the Kahalalide F family currently in phase I and II clinical development $[100,101]$. Among the various chemical class such as alkaloids, terpenoids, polyketide, macrocyclic lactone, peptide and proteins from marine environment including marine invertebrates could inhibits cell growth signal, induces apoptosis, inhibits invasion and metastasis of cancer [102-104]. The increasing interest in CAM among cancer patients may be due to limitations of conventional cancer treatment; therefore, marine invertebrate derived natural products are alternate way for the therapy for cancer. List of anticancer natural products is listed in Table 3.

\section{Conclusion}

There exists a great need for new, effective, and safe treatments of chronic diseases such as cancer, arthritis, osteoporosis, cardiovascular diseases, chronic inflammation, and Alzheimer's disease. Marine invertebrate derived natural products provide an excellent opportunity to study diverse and unique compounds not readily accessible from any other source leading to expansion of the pharmaceutical pipeline. Novel products from marine invertebrates exhibit potent activity in various in vitro and in vivo assays geared towards discovering pharmaceutical leads in these areas. The identification and development of natural compounds and their derivatives have greatly contributed to this progress and many of these compounds are now being used in clinical practice. Nature is still today a rich source of active principles against various diseases. Research results both testify to the evolution of knowledge coming from pharmacognosy and its historical roots in ancient medicine, and to the great possibilities of future progress by means of a rational, natural productbased drug discovery approach. Marine invertebrate's derived natural products will become a more significant part of the pipeline and alternate medicines for antiinflammatory and chronic diseases.

\section{Conflict of Interests}

The authors declare that there is no conflict of interests.

\section{Acknowledgment}

This study was supported by a grant from the Marine Bioprocess Research Center of the Marine Biotechnology
Program funded by the Ministry of Oceans and Fisheries, Republic of Korea.

\section{References}

[1] S. Mendis, K. Fukino, A. Cameron et al., "The availability and affordability of selected essential medicines for chronic diseases in six low- and middle-income countries," Bulletin of the World Health Organization, vol. 85, no. 4, pp. 279-288, 2007.

[2] H. Tunstall-Pedoe, "Preventing chronic diseases: a vital investment: WHO global report. Geneva: World Health Organization, 2005, International Journal of Epidemiology, vol. 35, no. 4, p. 1107, 2006.

[3] H.-K. Biesalski, L. O. Dragsted, I. Elmadfa et al., "Bioactive compounds: definition and assessment of activity," Nutrition, vol. 25, no. 11-12, pp. 1202-1205, 2009.

[4] P. Honkanen, "Consumer acceptance of (marine) functional food," Marine Functional Food, vol. 1, pp. 141-154, 2009.

[5] R. S. Rasmussen and M. T. Morrissey, "Marine biotechnology for production of food ingredients," Advances in Food and Nutrition Research, vol. 52, pp. 237-292, 2007.

[6] M. Plaza, A. Cifuentes, and E. Ibáñez, "In the search of new functional food ingredients from algae," Trends in Food Science and Technology, vol. 19, no. 1, pp. 31-39, 2008.

[7] J. W. Blunt, B. R. Copp, R. A. Keyzers, M. H. G. Munro, and M. R. Prinsep, "Marine natural products," Natural Product Reports, vol. 29, no. 2, pp. 144-222, 2012.

[8] M. Donia and M. T. Hamann, "Marine natural products and their potential applications as anti-infective agents," Lancet Infectious Diseases, vol. 3, no. 6, pp. 338-348, 2003.

[9] B. Haefner, "Drugs from the deep: marine natural products as drug candidates," Drug Discovery Today, vol. 8, no. 12, pp. 536544, 2003.

[10] D. J. Faulkner, "Biomedical uses for natural marine chemicals," Oceanus, vol. 35, pp. 29-35, 1992.

[11] P. McCarthy and S. Pomponi, "A search for new pharmaceutical drugs from marine organisms," Marine Biomedical Research, vol. 22, pp. 1-2, 2004.

[12] A. Harvey, "Strategies for discovering drugs from previously unexplored natural products," Drug Discovery Today, vol. 5, no. 7, pp. 294-300, 2000.

[13] D. J. Newman and G. M. Cragg, "Natural products as sources of new drugs over the last 25 years," Journal of Natural Products, vol. 70, no. 3, pp. 461-477, 2007.

[14] D. J. Newman and G. M. Cragg, "Natural products as sources of new drugs over the 30 years from 1981 to 2010," Journal of Natural Products, vol. 75, no. 3, pp. 311-335, 2012.

[15] M. S. Butler, "Natural products to drugs: natural product derived compounds in clinical trials," Natural Product Reports, vol. 22, no. 2, pp. 162-195, 2005.

[16] M. C. Leal, C. Madeira, C. A. Brandão, J. Puga, and R. Calado, "Bioprospecting of marine invertebrates for new natural products-a chemical and zoogeographical perspective," Molecules, vol. 17, no. 8, pp. 9842-9854, 2012.

[17] M. L. Wu, Y. Ho, C. Y. Lin, and S. F. Yet, "Heme oxygenase-1 in inflammation and cardiovascular disease," American Journal of Cardiovascular Disease, vol. 1, no. 2, pp. 150-158, 2011.

[18] J. Lunn and H. E. Theobald, "The health effects of dietary unsaturated fatty acids," Nutrition Bulletin, vol. 31, no. 3, pp. 178224, 2006. 
[19] K. Miyashita, "Function of marine carotenoids," Forum of Nutrition, vol. 61, pp. 136-146, 2009.

[20] S. Perdicaris, T. Vlachogianni, and A. Valavanidis, "Bioactive natural substances from marine sponges new developments and prospects for future pharmaceuticals," Natural Products Chemistry \& Research, vol. 1, no. 3, pp. 1-8, 2013.

[21] I. Jaswir and H. A. Monsur, "Anti-inflammatory compounds of macro algae origin: a review," Journal of Medicinal Plant Research, vol. 5, no. 33, pp. 7146-7154, 2011.

[22] A. Aiello, F. Borrelli, R. Capasso, E. Fattorusso, P. Luciano, and M. Menna, "Conicamin, a novel histamine antagonist from the mediterranean tunicate Aplidium conicum," Bioorganic and Medicinal Chemistry Letters, vol. 13, no. 24, pp. 4481-4483, 2003.

[23] M.-P. Sauviat, J. Vercauteren, N. Grimaud et al., "Sensitivity of cardiac background inward rectifying $\mathrm{K}^{+}$outward current (IK1) to the alkaloids lepadiformines A, B, and C," Journal of Natural Products, vol. 69, no. 4, pp. 558-562, 2006.

[24] S. Aoki, Y. Ye, K. Higuchi et al., "Novel neuronal nitric oxide synthase (nNOS) selective inhibitor, aplysinopsin-type indole alkaloid, from marine sponge Hyrtios erecta," Chemical and Pharmaceutical Bulletin, vol. 49, no. 10, pp. 1372-1374, 2001.

[25] K. A. El Sayed, A. A. Khalil, M. Yousaf et al., "Semisynthetic studies on the manzamine alkaloids," Journal of Natural Products, vol. 71, no. 3, pp. 300-308, 2008.

[26] H. Kobayashi, K. Kitamura, K. Nagai et al., "Carteramine A, an inhibitor of neutrophil chemotaxis, from the marine sponge Stylissa carteri," Tetrahedron Letters, vol. 48, no. 12, pp. 21272129, 2007.

[27] A. N. Pearce, E. W. Chia, M. V. Berridge et al., "Antiinflammatory thiazine alkaloids isolated from the New Zealand ascidian Aplidium sp.: inhibitors of the neutrophil respiratory burst in a model of gouty arthritis," Journal of Natural Products, vol. 70, no. 6, pp. 936-940, 2007.

[28] A. N. Pearce, E. W. Chia, M. V. Berridge et al., "E/Z-rubrolide $\mathrm{O}$, an anti-inflammatory halogenated furanone from the New Zealand ascidian Synoicum n. sp.," Journal of Natural Products, vol. 70, no. 1, pp. 111-113, 2007.

[29] C.-H. Chao, Z.-H. Wen, Y.-C. Wu, H.-C. Yeh, and J.-H. Sheu, "Cytotoxic and anti-inflammatory cembranoids from the soft coral Lobophytum crassum," Journal of Natural Products, vol. 71, no. 11, pp. 1819-1824, 2008.

[30] S.-Y. Cheng, Z.-H. Wen, S.-F. Chiou et al., "Durumolides AE, anti-inflammatory and antibacterial cembranolides from the soft coral Lobophytum durum," Tetrahedron, vol. 64, no. 41, pp. 9698-9704, 2008.

[31] Y.-C. Shen, Y.-H. Chen, T.-L. Hwang, J.-H. Guh, and A. T. Khalil, "Four new briarane diterpenoids from the gorgonian coral Junceella fragilis," Helvetica Chimica Acta, vol. 90, no. 7, pp. 1391-1398, 2007.

[32] M. H. Kossuga, A. M. Nascimento, J. Q. Reimão et al., "Antiparasitic, antineuroinflammatory, and cytotoxic polyketides from the marine sponge Plakortis angulospiculatus collected in Brazil," Journal of Natural Products, vol. 71, no. 3, pp. 334-339, 2008.

[33] World Health Organization, International Society of Hypertension Writing Group, "2003 World Health Organization (WHO)/International Society of Hypertension (ISH) statement on management of hypertension," Journal of Hypertension, vol. 21, no. 11, pp. 1983-1992, 2003.

[34] E. L. Cooper, "Drug discovery, CAM and natural products," Evidence-Based Complementary and Alternative Medicine, vol. 1, no. 3, pp. 215-217, 2004.
[35] P. Stead, S. Hiscox, P. S. Robinson et al., "Eryloside F, a novel penasterol disaccharide possessing potent thrombin receptor antagonist activity," Bioorganic and Medicinal Chemistry Letters, vol. 10, no. 7, pp. 661-664, 2000.

[36] S. Chackalamannil, "Thrombin receptor antagonists as novel therapeutic targets," Current Opinion in Drug Discovery and Development, vol. 4, no. 4, pp. 417-427, 2001.

[37] D. Sipkema, M. C. R. Franssen, R. Osinga, J. Tramper, and R. H. Wijffels, "Marine sponges as pharmacy," Marine Biotechnology, vol. 7, no. 3, pp. 142-162, 2005.

[38] M. Kuramoto, C. Tong, K. Yamada, T. Chiba, Y. Hayashi, and D. Uemura, "Halichlorine, an inhibitor of VCAM-1 induction from the marine sponge Halichondria okadai Kadota," Tetrahedron Letters, vol. 37, no. 22, pp. 3867-3870, 1996.

[39] H. Arimoto, I. Hayakawa, M. Kuramoto, and D. Uemura, "Absolute stereocmemistry of halichlorine; a potent inhibitor of VCAM-1 induction," Tetrahedron Letters, vol. 39, no. 8, pp. 861862, 1998.

[40] K. Y. Kim, K. A. Nam, H. Kurihara, and S. M. Kim, "Potent $\alpha$-glucosidase inhibitors purified from the red alga Grateloupia elliptica," Phytochemistry, vol. 69, no. 16, pp. 2820-2825, 2008.

[41] P. Zimmet, K. G. M. M. Alberti, and J. Shaw, "Global and societal implications of the diabetes epidemic," Nature, vol. 414, no. 6865, pp. 782-787, 2001.

[42] N. Tewari, V. K. Tiwari, R. C. Mishra et al., "Synthesis and bioevaluation of glycosyl ureas as $\alpha$-glucosidase inhibitors and their effect on mycobacterium," Bioorganic and Medicinal Chemistry, vol. 11, no. 13, pp. 2911-2922, 2003.

[43] K. Agyemang, L. Han, E. Liu, Y. Zhang, T. Wang, and $\mathrm{X}$. Gao, "Recent advances in astragalus membranaceus antidiabetic research: pharmacological effects of its phytochemical constituents," Evidence-Based Complementary and Alternative Medicine, vol. 2013, Article ID 654643, 9 pages, 2013.

[44] Y. Nakao, T. Uehara, S. Matunaga, N. Fusetani, and R. W. M. van Soest, "Callyspongynic acid, a polyacetylenic acid which inhibits $\alpha$-glucosidase, from the marine sponge Callyspongia truncata," Journal of Natural Products, vol. 65, no. 6, pp. 922924, 2002.

[45] H. E. Lebovitz, "Oral antidiabetic agents: the emergence of $\alpha$ glucosidase inhibitors," Drugs, vol. 44, no. 3, pp. 21-28, 1992.

[46] H. Yamazaki, D. A. Sumilat, S. Kanno et al., "A polybromodiphenyl ether from an Indonesian marine sponge Lamellodysidea herbacea and its chemical derivatives inhibit protein tyrosine phosphatase $1 \mathrm{~B}$, an important target for diabetes treatment," Journal of Natural Medicines, vol. 67, no. 4, pp. 730735, 2013.

[47] V. Venugopal, Marine Products for Healthcare: Functional and Bioactive Nutraceutical Compounds from the Ocean, CRC Press, 2009.

[48] A. M. Badger, M. N. Cook, B. A. Swift, T. M. Newman-Tarr, M. Gowen, and M. Lark, "Inhibition of interleukin-1-induced proteoglycan degradation and nitric oxide production in bovine articular cartilage/chondrocyte cultures by the natural product, hymenialdisine," Journal of Pharmacology and Experimental Therapeutics, vol. 290, no. 2, pp. 587-593, 1999.

[49] A. P. R. Lirani-Galvão and M. Lazaretti-Castro, "Physical approach for prevention and treatment of osteoporosis," Arquivos Brasileiros de Endocrinologia e Metabologia, vol. 54, no. 2, pp. 171-178, 2010.

[50] E. S. Orwoll and R. F. Klein, “Osteoporosis in men," Endocrine Reviews, vol. 16, no. 1, pp. 87-116, 1995. 
[51] J. Venkatesan and S.-K. Kim, "Osteoporosis treatment. Marine algal compounds," Advances in Food and Nutrition Research, vol. 64, pp. 417-427, 2011.

[52] S. Fukuzawa, Y. Hayashi, and D. Uemura, "The isolation and structures of five new alkaloids, Norzoanthamine, Oxyzoanthamine, Norzoanthaminone, Cyclozoanthamine and Epinorzoanthamine," Heterocyclic Communications, vol. 1, no. 2, pp. 207-214, 1995.

[53] M. Kinugawa, S. Fukuzawa, and K. Tachibana, "Skeletal protein protection: the mode of action of an anti-osteoporotic marine alkaloid, norzoanthamine," Journal of Bone and Mineral Metabolism, vol. 27, no. 3, pp. 303-314, 2009.

[54] F. Chiappelli, A. M. Navarro, D. R. Moradi, E. Manfrini, and P. Prolo, "Evidence-based research in complementary and alternative medicine III: treatment of patients with Alzheimer's disease," Evidence-Based Complementary and Alternative Medicine, vol. 3, no. 4, pp. 411-424, 2006.

[55] R. Langjae, S. Bussarawit, S. Yuenyongsawad, K. Ingkaninan, and A. Plubrukarn, "Acetylcholinesterase-inhibiting steroidal alkaloid from the sponge Corticium sp.," Steroids, vol. 72, no. 910, pp. 682-685, 2007.

[56] M. M. Esiri, "The interplay between inflammation and neurodegeneration in CNS disease," Journal of Neuroimmunology, vol. 184, no. 1-2, pp. 4-16, 2007.

[57] D. Tasdemir, R. Mallon, M. Greenstein et al., "Aldisine alkaloids from the Philippine sponge Stylissa massa are potent inhibitors of mitogen-activated protein kinase kinase-1 (MEK-1)," Journal of Medicinal Chemistry, vol. 45, no. 2, pp. 529-532, 2002.

[58] L. Meijer, A.-M. W. H. Thunnissen, A. W. White et al., "Inhibition of cyclin-dependent kinases, GSK-3 $\beta$ and CK1 by hymenialdisine, a marine sponge constituent," Chemistry and Biology, vol. 7, no. 1, pp. 51-63, 2000.

[59] W. F. Chen, C. Chakraborty, C. S. Sung et al., "Neuroprotection by marine-derived compound, 11-dehydrosinulariolide, in an in vitro Parkinson's model: a promising candidate for the treatment of Parkinson's disease," Naunyn-Schmiedeberg's Archives of Pharmacology, vol. 385, no. 3, pp. 265-275, 2012.

[60] M. D. Furler, T. R. Einarson, S. Walmsley, M. Millson, and R. Bendayan, "Use of complementary and alternative medicine by HIV-infected outpatients in Ontario, Canada," AIDS Patient Care and STDs, vol. 17, no. 4, pp. 155-168, 2003.

[61] L.-A. Tziveleka, C. Vagias, and V. Roussis, "Natural products with anti-HIV activity from marine organisms," Current Topics in Medicinal Chemistry, vol. 3, no. 13, pp. 1512-1535, 2003.

[62] J. Yasuhara-Bell and Y. Lu, "Marine compounds and their antiviral activities," Antiviral Research, vol. 86, no. 3, pp. 231240, 2010.

[63] W. E. G. Müller and H. C. Schröder, "Cell biological aspects of HIV-1 infection: effect of the anti-HIV-1 agent avarol," International Journal of Sports Medicine, vol. 12, supplement 1, pp. S43-S49, 1991.

[64] A. Rudi, T. Yosief, S. Loya, A. Hizi, M. Schleyer, and Y. Kashman, "Clathsterol, a novel anti-HIV-1 RT sulfated sterol from the sponge Clathria species," Journal of Natural Products, vol. 64, no. 11, pp. 1451-1453, 2001.

[65] M. A. Rashid, K. R. Gustafson, L. K. Cartner, N. Shigematsu, L. K. Pannell, and M. R. Boyd, "Microspinosamide, a new HIVinhibitory cyclic depsipeptide from the marine sponge Sidonops microspinosa," Journal of Natural Products, vol. 64, no. 1, pp. 117121, 2001.

[66] L. Chang, N. F. Whittaker, and C. A. Bewley, "Crambescidin 826 and dehydrocrambine A: new polycyclic guanidine alkaloids from the marine sponge Monanchora sp. that inhibit HIV-1 fusion," Journal of Natural Products, vol. 66, no. 11, pp. 14901494, 2003.

[67] L. Chill, A. Rudi, M. Aknin, S. Loya, A. Hizi, and Y. Kashman, "New sesterterpenes from Madagascan Lendenfeldia sponges," Tetrahedron, vol. 60, no. 47, pp. 10619-10626, 2004.

[68] N. Oku, K. R. Gustafson, L. K. Cartner et al., "Neamphamide A, a new HIV-inhibitory depsipeptide from the Papua New Guinea marine sponge Neamphius huxleyi," Journal of Natural Products, vol. 67, no. 8, pp. 1407-1411, 2004.

[69] T. Venkateshwar Goud, N. Srinivasa Reddy, N. Raghavendra Swamy, T. Siva Ram, and Y. Venkateswarlu, "Anti-HIV active petrosins from the marine sponge Petrosia similis," Biological and Pharmaceutical Bulletin, vol. 26, no. 10, pp. 1498-1501, 2003.

[70] B. C. M. Potts, D. J. Faulkner, J. A. Chan et al., "Didemnaketals A and B, HIV-1 protease inhibitors from the ascidian Didemnum sp.," Journal of the American Chemical Society, vol. 113, no. 16, pp. 6321-6322, 1991.

[71] S. S. Mitchell, D. Rhodes, F. D. Bushman, and D. J. Faulkner, "Cyclodidemniserinol trisulfate, a sulfated serinolipid from the Palauan ascidian Didemnum guttatum that inhibits HIV-1 integrase," Organic Letters, vol. 2, no. 11, pp. 1605-1607, 2000.

[72] R. J. Andersen, D. J. Faulkner, C. H. He, G. D. van Duyne, and J. Clardy, "Metabolites of the marine prosobranch mollusc Lamellaria sp.", Journal of the American Chemical Society, vol. 107, no. 19, pp. 5492-5495, 1985.

[73] M. V. R. Reddy, M. R. Rao, D. Rhodes et al., "Lamellarin $\alpha$ 20 -sulfate, an inhibitor of HIV-1 integrase active against HIV1 virus in cell culture," Journal of Medicinal Chemistry, vol. 42, no. 11, pp. 1901-1907, 1999.

[74] T. Miyata, F. Tokunaga, T. Yoneya et al., "Antimicrobial peptides, isolated from horseshoe crab hemocytes, tachyplesin II, and polyphemusins I and II: chemical structures and biological activity," Journal of Biochemistry, vol. 106, no. 4, pp. 663-668, 1989.

[75] M. Morimoto, H. Mori, T. Otake et al., "Inhibitory effect of tachyplesin I on the proliferation of human immunodeficiency virus in vitro," Chemotherapy, vol. 37, no. 3, pp. 206-211, 1991.

[76] A. M. S. Mayer, A. D. Rodríguez, R. G. S. Berlinck, and N. Fusetani, "Marine pharmacology in 2007-8: marine compounds with antibacterial, anticoagulant, antifungal, antiinflammatory, antimalarial, antiprotozoal, antituberculosis, and antiviral activities; Affecting the immune and nervous system, and other miscellaneous mechanisms of action," Comparative Biochemistry and Physiology C, vol. 153, no. 2, pp. 191-222, 2011.

[77] N. J. Carter and S. J. Keam, “Trabectedin: a review of its use in soft tissue sarcoma and ovarian cancer," Drugs, vol. 70, no. 3, pp. 355-376, 2010.

[78] F. A. Villa and L. Gerwick, "Marine natural product drug discovery: leads for treatment of inflammation, cancer, infections, and neurological disorders," Immunopharmacology and Immunotoxicology, vol. 32, no. 2, pp. 228-237, 2010.

[79] M. P. Prado, Y. R. Torres, R. G. S. Berlinck et al., "Effects of marine organisms extracts on microtubule integrity and cell cycle progression in cultured cells," Journal of Experimental Marine Biology and Ecology, vol. 313, no. 1, pp. 125-137, 2004.

[80] B. Pardo, L. Paz-Ares, J. Tabernero et al., "Phase I clinical and pharmacokinetic study of kahalalide $\mathrm{F}$ administered weekly as a 1-hour infusion to patients with advanced solid tumors," Clinical Cancer Research, vol. 14, no. 4, pp. 1116-1123, 2008. 
[81] M. Provencio, A. Sánchez, J. Gasent, P. Gómez, and R. Rosell, "Cancer treatments: can we find treasures at the bottom of the sea?” Clinical Lung Cancer, vol. 10, no. 4, pp. 295-300, 2009.

[82] M. Schumacher, C. Cerella, S. Eifes et al., "Heteronemin, a spongean sesterterpene, inhibits TNF $\alpha$-induced NF- $\kappa$ B activation through proteasome inhibition and induces apoptotic cell death," Biochemical Pharmacology, vol. 79, no. 4, pp. 610-622, 2010.

[83] V. Edwards, K. Benkendorff, and F. Young, "Marine compounds selectively induce apoptosis in female reproductive cancer cells but not in primary-derived human reproductive granulosa cells," Marine Drugs, vol. 10, no. 1, pp. 64-83, 2012.

[84] N. Dias, H. Vezin, A. Lansiaux, and C. Bailly, “Topoisomerase inhibitors of marine origin and their potential use as anticancer agents," in DNA Binders and Related Subjects, vol. 253 of Topics in Current Chemistry, pp. 89-108, Springer, Berlin, Germany, 2005.

[85] I. Bonnard, N. Bontemps, S. Lahmy et al., "Binding to DNA and cytotoxic evaluation of ascididemin, the major alkaloid from the Mediterranean ascidian Cystodytes dellechiajei," Anti-Cancer Drug Design, vol. 10, no. 4, pp. 333-346, 1995.

[86] L. Dassonneville, N. Wattez, B. Baldeyrou et al., "Inhibition of topoisomerase II by the marine alkaloid ascididemin and induction of apoptosis in leukemia cells," Biochemical Pharmacology, vol. 60, no. 4, pp. 527-537, 2000.

[87] C. Tardy, M. Facompré, W. Laine et al., “Topoisomerase Imediated DNA cleavage as a guide to the development of antitumor agents derived from the marine alkaloid lamellarin D: triester derivatives incorporating amino acid residues," Bioorganic and Medicinal Chemistry, vol. 12, no. 7, pp. 1697-1712, 2004.

[88] C. Ballot, J. Kluza, A. Martoriati et al., "Essential role of mitochondria in apoptosis of cancer cells induced by the marine alkaloid Lamellarin D," Molecular Cancer Therapeutics, vol. 8, no. 12, pp. 3307-3317, 2009.

[89] L. Schyschka, A. Rudy, I. Jeremias, N. Barth, G. R. Pettit, and A. M. Vollmar, "Spongistatin 1: a new chemosensitizing marine compound that degrades XIAP," Leukemia, vol. 22, no. 9, pp. 1737-1745, 2008.

[90] S.-H. Lee, B. Ryu, J.-Y. Je, and S.-K. Kim, "Diethylaminoethyl chitosan induces apoptosis in HeLa cells via activation of caspase- 3 and p53 expression," Carbohydrate Polymers, vol. 84, no. 1, pp. 571-578, 2011.

[91] K. J. Hale and S. Manaviazar, "New approaches to the total synthesis of the bryostatin antitumor macrolides," ChemistryAn Asian Journal, vol. 5, no. 4, pp. 704-754, 2010.

[92] H. J. Mackay and C. J. Twelves, "Targeting the protein kinase C family: are we there yet?” Nature Reviews Cancer, vol. 7, no. 7, pp. 554-562, 2007.

[93] Y. Hirata and D. Uemura, "Halichondrins-antitumor polyether macrolides from a marine sponge," Pure and Applied Chemistry, vol. 58, no. 5, pp. 701-710, 1986.

[94] A. Jimeno, "Eribulin: rediscovering tubulin as an anticancer target," Clinical Cancer Research, vol. 15, no. 12, pp. 3903-3905, 2009.

[95] G. M. Cragg and D. J. Newman, "Plants as a source of anticancer agents," Journal of Ethnopharmacology, vol. 100, no. 1-2, pp. 72-79, 2005.

[96] P. E. Morande, S. R. Zanetti, M. Borge et al., "The cytotoxic activity of Aplidin in chronic lymphocytic leukemia (CLL) is mediated by a direct effect on leukemic cells and an indirect effect on monocyte-derived cells," Investigational New Drugs, vol. 30, no. 5, pp. 1830-1840, 2012.

[97] J. E. Coleman, E. Dilip de Silva, F. Kong, R. J. Andersen, and T. M. Allen, "Cytotoxic peptides from the marine sponge Cymbastela sp.” Tetrahedron, vol. 51, no. 39, pp. 10653-10662, 1995.

[98] W. R. Gamble, N. A. Durso, R. W. Fuller et al., "Cytotoxic and tubulin-interactive hemiasterlins from Auletta $s p$. and Siphonochalina spp. sponges," Bioorganic and Medicinal Chemistry, vol. 7, no. 8, pp. 1611-1615, 1999.

[99] H. J. Anderson, J. E. Coleman, R. J. Andersen, and M. Roberge, "Cytotoxic peptides hemiasterlin, hemiasterlin A and hemiasterlin B induce mitotic arrest and abnormal spindle formation," Cancer Chemotherapy and Pharmacology, vol. 39, no. 3, pp. 223-226, 1997.

[100] R. Salazar, H. Cortés-Funes, E. Casado et al., "Phase I study of weekly kahalalide $\mathrm{F}$ as prolonged infusion in patients with advanced solid tumors," Cancer Chemotherapy and Pharmacology, vol. 72, no. 1, pp. 1-9, 2013.

[101] M. Serova, A. de Gramont, I. Bieche et al., "Predictive factors of sensitivity to elisidepsin, a novel Kahalalide F-derived marine compound," Marine Drugs, vol. 11, no. 3, pp. 944-959, 2013.

[102] M. Schumacher, M. Kelkel, M. Dicato, and M. Diederich, "A survey of marine natural compounds and their derivatives with anti-cancer activity reported in 2010," Molecules, vol. 16, no. 7, pp. 5629-5646, 2011.

[103] W. R. Sawadogo, M. Schumacher, M. H. Teiten, C. Cerella, M. Dicato, and M. Diederich, "A survey of marine natural compounds and their derivatives with anti-cancer activity reported in 2011," Molecules, vol. 18, no. 4, pp. 3641-3673, 2013.

[104] K. Senthilkumar and S. K. Kim, "Cell survival and apoptosis signaling as therapeutic target for cancer: marine bioactive compounds," International Journal of Molecular Sciences, vol. 14, no. 2, pp. 2334-2354, 2013. 


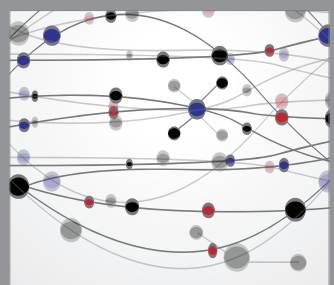

The Scientific World Journal
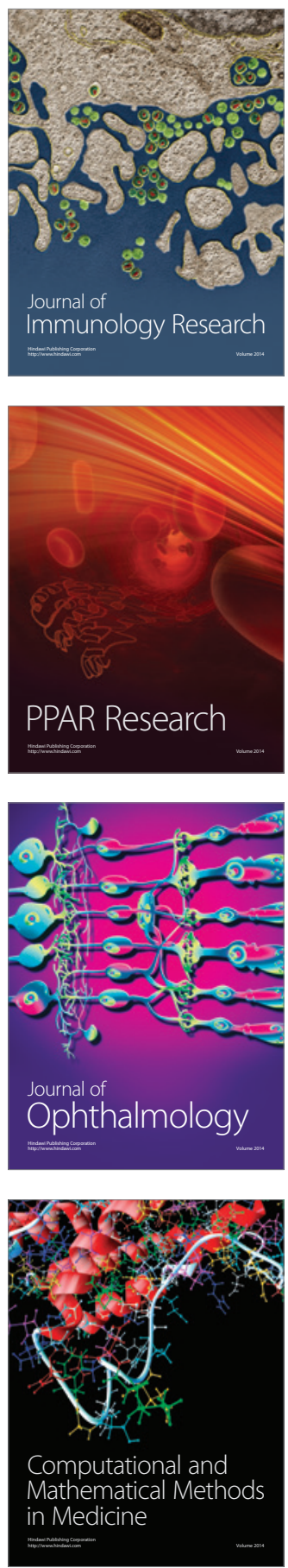

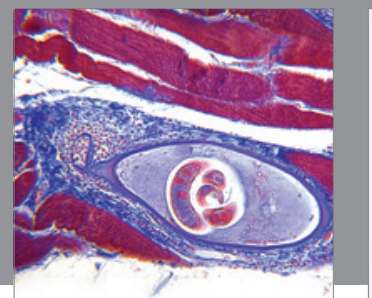

Gastroenterology

Research and Practice
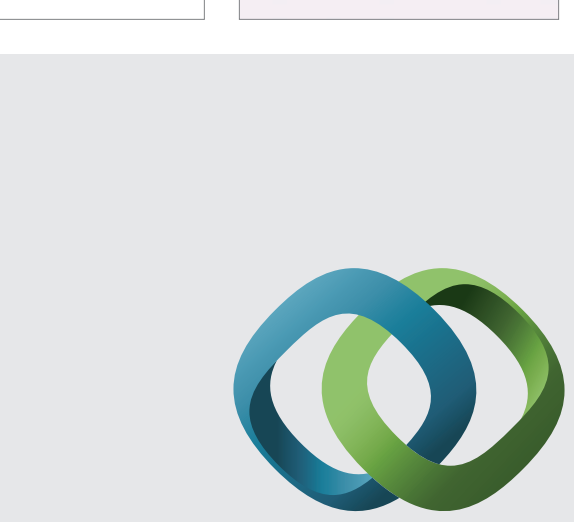

\section{Hindawi}

Submit your manuscripts at

http://www.hindawi.com
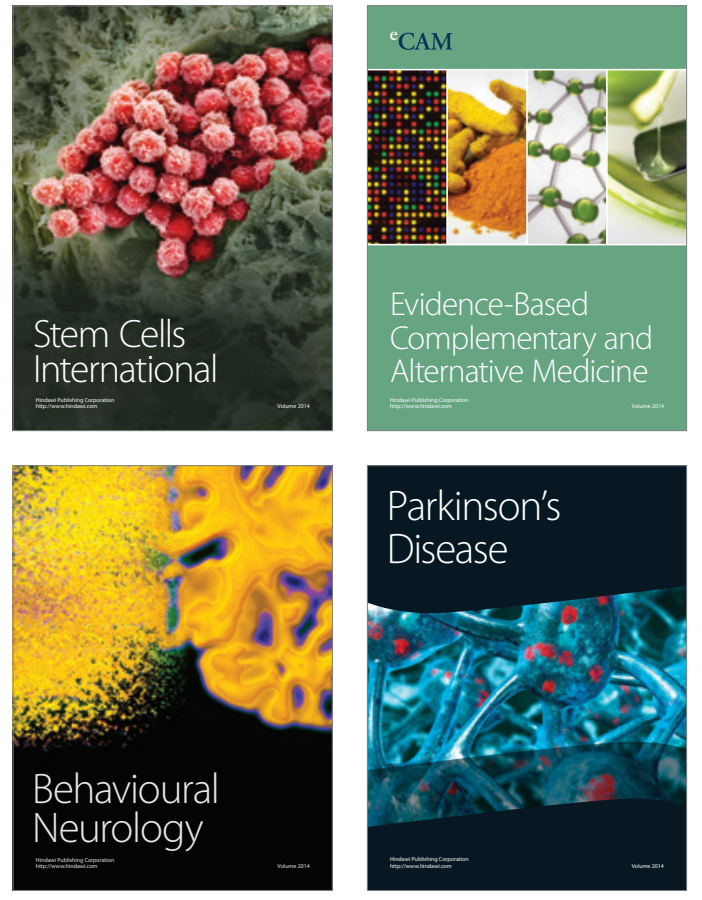
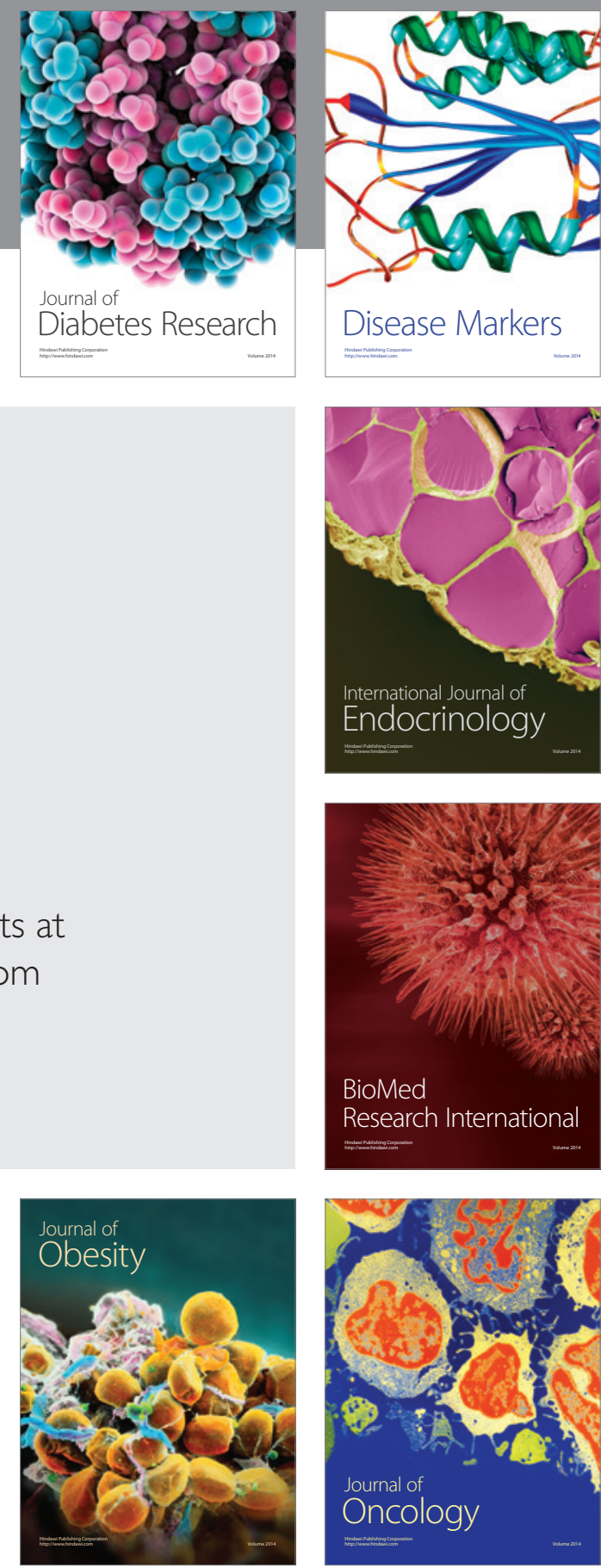

Disease Markers
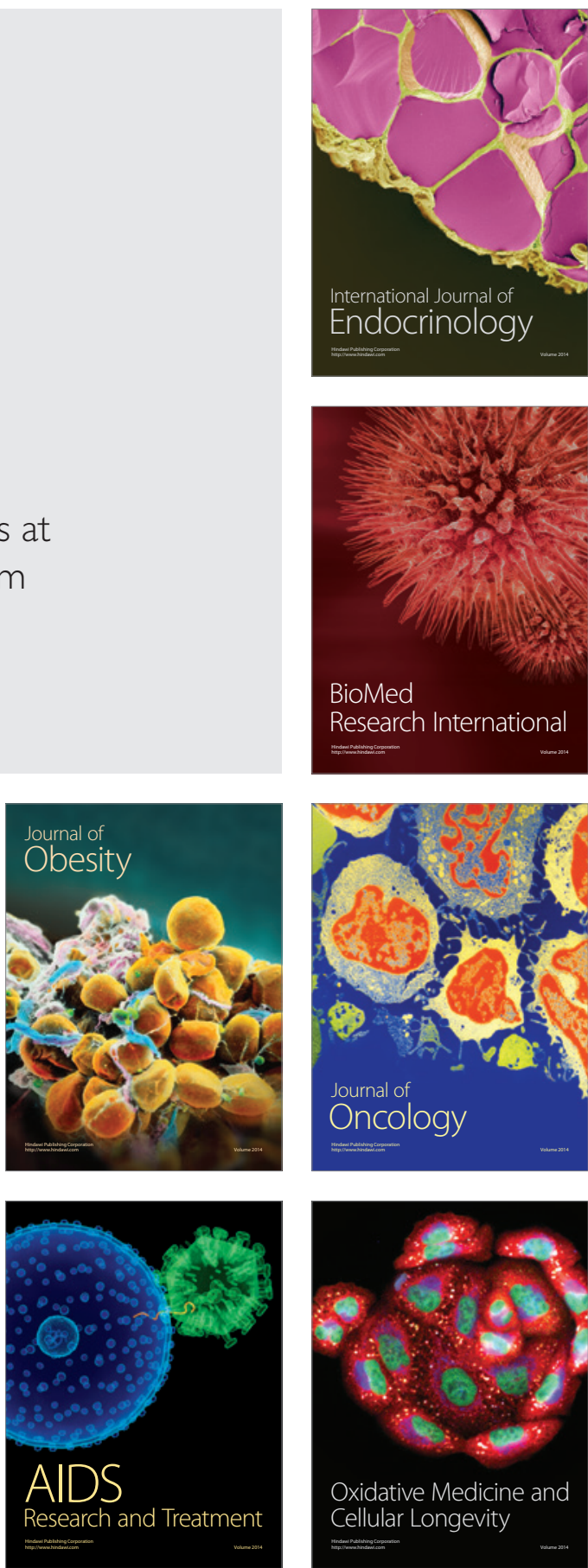